http://www.pakjas.com.pk

\title{
Evaluation of parasitic potential of Anisopteromalus calandrae (Howard) against Callosobruchus maculatus (F.), Rhyzopertha dominica (F.) and Sitophilus oryzae (L.) in grains treated with diatomaceous earths
}

\author{
Khurram Mahmood Sultan Kamboh*, Muhammad Anjum Aqueel and Muhammad Abubakar Raza \\ Department of Entomology, University College of Agriculture, University of Sargodha, Pakistan \\ *Corresponding author's e-mail: ksultankamboh@gmail.com
}

\begin{abstract}
The herein reported study was conducted to evaluate the parasitic potential of Anisopteromalus calandrae (Howard) against larvae of Callosobruchus maculatus (F.), Rhyzopertha dominica (F.) and Sitophilus oryzae (L.) while, adult pests on the food medium treated with two formulations of diatomaceous earth (DE); Marine (Celite) and fresh water (Perma Guard) as grain protectants. The DE was applied at three dose rates i.e., 200,400 and $600 \mathrm{ppm}$, at $25^{\circ} \mathrm{C}$ temperature and $65 \%$ relative humidity. Mortality and emergence of adults of tested insects and parasitoid were observed after 14 and 28 days of exposure respectivly. The highest mortality of C. maculatus was $43.37 \%$ against higher dose of Perma Guard (600 ppm) while the maximum mortality of $S$. oryzae was recorded $39.56 \%$ on application of Celite $(600 \mathrm{ppm})$. The maximum mortality of A. calandrae parasitoid was observed $66.86 \%$ in S. oryzae infested grains treated with higher dose of Perma Guard (600 ppm), while 63.81\% mortality of parasitoid was observed in S. oryzae infested grains at higher dose of Celite DE (600 ppm). The Perma Guard effectively controls population of tested insect's mortality than the Celite. The highest emergence of $C$ maculatus observed was $62.44 \%$ at lower dose of $200 \mathrm{ppm}$ of Perma Guard DE while the highest emergence recorded on application of Celite was $60.66 \%$ from C. maculatus. The highest emergence of A. calandrae was $65.65 \%$ from $S$. oryzae at lower dose of $200 \mathrm{ppm}$ of Perma Guard DE while the highest emergence of parasitoid recorded on application of Celite was found 60.66\% at lower dose of $200 \mathrm{ppm}$ from $C$ maculatus. The emergence of tested insects and parasitoid increased with the decrease in dose rate of DE in most of the tested combinations. Higher dose (600 ppm) of both DE (Celite and Perma Guard) used in experiment showed mortality of tested insects and parasitoid activity of Anisopteromalus calandrae and furthermore release of A. calandrae on host insects would be adversely affected by use of diatomaceous earth product on stored grains. The experiments were carried out in laboratory of Grain Research, Training and Storage Management cell, Department of Entomology, University of Agriculture Faisalabad.
\end{abstract}

Keywords: Anisopteromalus calandrae, Callosobruchus maculatus, Diatomaceous earth, Parasitism, Rhyzopertha dominica and Sitophilus oryzae.

\section{INTRODUCTION}

Pulse beetle, Callosobruchus maculates L. (Coleoptera: Bruchidae) also known as dhora beetle is the most destructive cosmopolitan pest of stored gram. It is a pest of stored pulses cause $12-13 \%$ loss by feeding the protein contents of grains. C. maculates causes up to $10 \%$ damage to stored chick pea and up to $90 \%$ loss to stored gram. (Sidra-Tul-Muntaha et al., 2017)

Losses caused by the insect pests may reach up to $30 \%$ during storage. About 2-6\% food grain production of Pakistan is lost every year during storage by stored grain insect pests including Rhyzopertha dominica (Coleoptera: bostruchidae)
(Fabricious 1792), Sitophilus oryzae (Coleoptera: Curculionidae) (Linnaeus, 1763) (Wakil, W. and A. Shabbir, 2013)

Diatomaceous earths (DEs) used for insect pest mortality, because of unique mode of action, no or low mammalian toxicity (Subramanyam and Roesli, 2000). A. calandrae females avoid strongly against treatment of Protect-It on wheat and a significantly prefers parasitizing weevils in untreated wheat (Perez-mendoza 1999). Its affectivity depends on type of insects, stored commodity and environmental factors (Athanassiou et al., 2011). Athanassiou et al. (2003) found the mortality effect of DE SilicoSec $®$ against Sitophilus oryzae (L.) on two commodities at 1000

Nawaz, H., M.A. Ali, R.M. Atif, A. Nawaz and A. Abbas. 2021. Incidence of fusarium wilt in major tomato growing areas of Punjab. Pak. J. Agri. Sci.58:11611167.

[Received 16-4-2021; Accepted 12-Jul 2021; Published (online) 21 Sep 2021]

(C) (1)

Attribution 4.0 International (CC BY 4.0) 
ppm. Efficacy depends upon the Source of DE but basically they are soft rock fossilized algae called diatoms. (Kavallieratos et al., 2005). Mode of action for DE associated with the removal of the insect's cuticular waxes resulted in mortality from desiccation (Athanassiou et al., 2005). For protection of seed, it is usually mixed into the grain as a powder. The use of pesticides increases environmental pollution, depletion of ozone, so there is need of time for nonchemical pest control methods. DE is biodegradable and does not show toxic effect (Arthur, 2002).

Regardless of the non-availability of methyl bromide and continuous use of aluminum phosphide as fumigant to control stored product pests (Kavallieratos et al., 2007), out of many available control tactics, only few have Protect-it been comprehensively assessed. nsect pest can be controlled by different methods like biological (Hoedjes et al., 2011), chemical (Ishii and Shimada 2012) and physical control tactics (Ghimire and Phillips 2008; Ishii 2008 Numerous kind of hymenopteran parasitoids including Lariophagus distinguendus (F), (Hymenoptera: Pteromalidae), Anisopteromalus calandrae, have been used to manage stored grain insect pests (Gokhman, 2003; Sasakawa et al., 2012). These species have a highly developed ability to detect prey and can attack numerous tested species. Both L. distinguendus and $A$. calandrae are quite effective in managing these storage pests (Konishi et al., 2004).The female of wasps uses certain clues to locate the larvae that are developed mostly in the inner portion of the grains and detect pest movement. It also detects sound of host feeding, before parasitizing. Once the larvae found, the female wasp uses to oviposit by drilling into the grain, kill the host larvae and oviposit an egg on it. The female of $A$. calandrae prefers to oviposit on the later stages of Sitophilus oryzae at lab condition $25 \pm 5^{\circ} \mathrm{C}$ and $65 \pm 5 \%$ RH (Islam et al., 2003). The mode of laying egg of female wasp is inserting the ovipositor into seed up to the body of host insect. The larvae of wasp on hatching feed on the fluids of larval body of pest. The wasp possess three larval stages, followed by pupal and finally adult. Emerging adults have tremendous ability to kill the insect pests (Islam, 2006).

Keeping in view the above facts, the herein reported study was conducted to evaluate the application of the Diatomaceous Earths (DE) along with bio-control agent (Anisopteromalus calandrae) and the efficacy in term of reducing pest population.

\section{MATERIALS AND METHODS}

Insects Pest collections: Three insect pests namely, Callosobruchus maculatus (F.), Sitophilus oryzae (L.); Rhyzopertha dominica (F.) were collected from farmer field, private and government storage department and reared in laboratory for several generations for the homogenous population that were used in further research. The experiments were carried out in laboratory of Grain Research,
Training and Storage Management cell, Department of Entomology, University of Agriculture Faisalabad.

Parasitoids: Adult females of Anisopteromalus calandrae were obtained from stock cultures (initially reared on cow pea grains) maintained in the laboratory at $25{ }^{\circ} \mathrm{C}$ and $75 \% \mathrm{RH}$ (Kavallieratos et al., 2005). The A. calandrae is a pteromalid wasp, easily reared in the laboratory at $25 \pm 5^{\circ} \mathrm{C}$ and $65 \pm 5 \%$ RH. The populations of parasitoid $A$. calandrae were released in the jar. In the plastic jars, clean cowpea grains was introduced and allowed to infest with larvae of $C$. maculates and $S$. oryzae in brown rice. Jars placed in incubators. The grains that receive this oviposition were collected and placed in other jar containing grubs population again and again for several generations in order to get the homogeneous parasitoid population.

Diatomaceous Earth: Different formulations of Marine (Celite, 80-90\% silica, with 2-4\% alumina and $0.5-2 \%$ iron oxide) (Sigma-Aldrich) and fresh water (Perma Guard $80 \%$ silica) (PubChem CID) DE were imported from USA. DE was used at the rate of 200, 400 and $600 \mathrm{ppm}$

Effect of diatomaceous earth on parasitic potential: Grains (wheat, rice and cowpea) were treated with DE at different concentration (200, 400 and $600 \mathrm{ppm}) 24 \mathrm{hr}$ before releasing the insect pests and $A$. calandrae. All the tests to examine parasitism of $A$. calandrae were conducted at temperature $30^{\circ} \mathrm{C}$ and replicated three times. Thirty (30) samples of adults of insect pests were introduced in a plastic box separately. Five pairs of $A$. calandrae were introduced into treatment, after 14 days alive or dead adults of pest data were noted and lateral larval stages of F1 progeny allowed to parasitize for 24 hours on the later stage of larvae of insect pest. Jars were placed in incubator under controlled conditions. The larvae of pests that receive this oviposition were observed till the parasitoid emergence. Mortality data for pest and parasitoid was collected after 14 days and Emergence data for pest and parasitoid was collected after 28 days.

Former to setting up of experiment the grains (wheat, rice and cowpea) were cleaned and disinfested by exposing to $60^{\circ} \mathrm{C}$ for three hours in an air-circulated oven. The treatments consisted of two DE formulations and three DE dose rates and an untreated control, each replicated three times. Lots of 150 $\mathrm{g}$ of wheat were treated with four dose rates of 0 (control), 200,400 and $600 \mathrm{mg} / \mathrm{kg}$ of each DE formulation. The lots were placed in $500 \mathrm{ml}$ capacity bottles and the above mentioned dose of DE was added in each lot. The bottles were shaken manually for 2 minutes to achieve an even distribution of the DE on the grains. Subsequently, three samples of $50 \mathrm{~g}$ of treated or control grains were taken from each lot, and placed in $250 \mathrm{ml}$ capacity glass jars. In each jar, thirty (30) adults of insect pests were introduced and then the jars were covered with perforated plastic lids fitted with filter papers to allow gaseous exchange. Five pairs of A. calandrae were introduced into treatment, allowed to parasitoid the later stage of larvae for $24 \mathrm{hr}$ on removal of alive or dead adults after 14 
days. The jars were kept under laboratory conditions at $30^{\circ} \mathrm{C}$ and $65 \% \mathrm{RH}$. Adult mortality of insect pest was assessed after 14 and emergence of parasitoids after 28 days of exposure.

Statistical Analysis: Collected data of parasitoid and tested insects were corrected by using Abbott's formula (Abbott, 1925). After that the treatments were compared by using analysis of variance (ANOVA) through Statistic 8.0. Treatment means were separated using Tukey Kramer HSD test at $\alpha=0.05$ level.

\section{RESULTS}

The results reveal that for fresh water DE the highest mortalities $43.37 \%, 30.81$ and $32.56 \%$ were recorded in 600 ppm concentration for $C$. maculatus, $R$. dominica and $S$. oryzae respectively. Lowest mortalities of 14.44, 11.05 and $16.86 \%$ were observed with 200 ppm concentration for $C$. maculatus, $R$. dominica and $S$. oryzae respectively. Mortalities of tested insects increased with an increase in DE concentration. C. maculatus showed higher mortality $43.37 \%$ at maximum dose as compared to other tested insects in bioassay (Fig. 1).

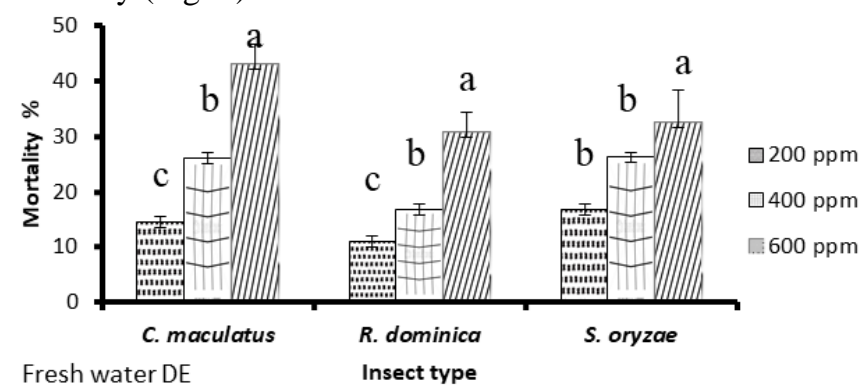

Figure 1. Comparison of means of percent mortality of tested insects, $C$. maculatus $(\mathrm{F}=25.39 ; P<0.001)$, $R$. dominica $(\mathrm{F}=9.54 ; P<0.001), S$. oryzae $(\mathrm{F}=4.28 ; P<0.001)$ at different dose (ppm) of Perma Guard diatomaceous earth after 14 days' time interval

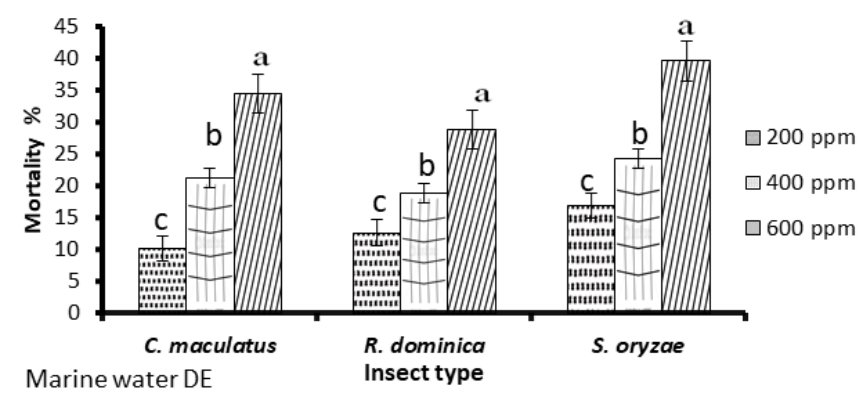

Figure 2. Comparison of means of percent mortality of tested insects, $C$. maculatus $(\mathrm{F}=25.39 ; P<0.001)$, R. dominica $(\mathrm{F}=9.54 ; \quad P<0.001), \quad$ S. oryzae $(\mathrm{F}=4.28 ; P<0.001)$ at different dose (ppm) of Celite diatomaceous earth after 14 days time interva
The results reveal that for marine water DE the highest mortalities 34.44, 28.81\% and 39.56\% were recorded in 600 ppm concentration for $C$. maculatus, $R$. dominica and $S$. oryzae respectively. Lowest mortalities $10.14 \%, 12.65 \%$ and $16.86 \%$ was observed with 200 ppm concentration for $C$. maculatus, $R$. dominica and $S$. oryzae respectively. Mortality of tested insects increases with the increase in DE concentration but significantly less than fresh water DE. $S$. oryzae showed higher mortality $39.56 \%$ at maximum dose as compared to other tested insects in bioassay (Fig. 2).

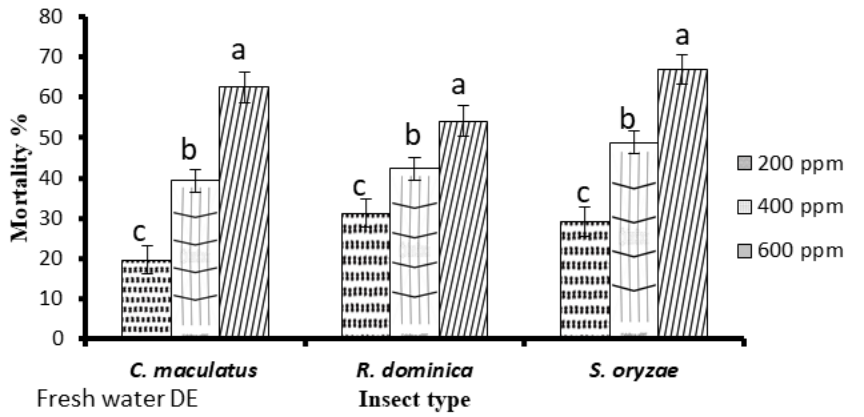

Figure 3. Comparison of means of percent mortality of Anisopteromalus calandrae on tested insects, $C$. maculatus $(\mathrm{F}=51.0 ; \quad P<0.001), \quad R$. dominica $(\mathrm{F}=11.6 ; P<0.001)$, S. oryzae $(\mathrm{F}=51.4 ; P<0.001)$ at different dose (ppm) of Perma Guard diatomaceous earth after 14 days time interval

The results reveal that for fresh water $\mathrm{DE}$ the highest mortalities 62.44, 54.11 and $66.86 \%$ were recorded in 600 ppm concentration for A. calandrae on $C$. maculatus, $R$. dominica and $S$. oryzae respectively. Lowest mortalities 19.66, 31.17 and 29.13 was observed with 200ppm concentration for A. calandrae on $C$. maculatus, $R$. dominica and $S$. oryzae respectively. Mortality of $A$. calandrae increases with the increase in DE concentration. S. oryzae shows higher mortality $66.86 \%$ at maximum dose in bioassay (Fig. 3).

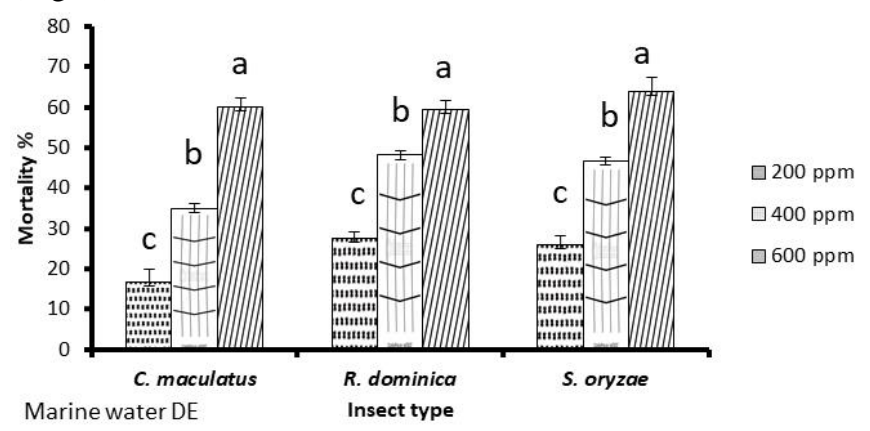

Figure 4. Comparison of means of percent mortality of Anisopteromalus calandrae on tested insects, $C$. maculatus $(\mathrm{F}=51.0 ; \quad P<0.001), \quad R$. dominica $(\mathrm{F}=11.6 ; P<0.001)$, S. oryzae $(\mathrm{F}=51.4 ; P<0.001)$ at different dose (ppm) of of Celite diatomaceous earth after 14 days time interval 
The results reveal that for marine water DE the highest mortalities 60.0, 59.34 and $63.81 \%$ were recorded in $600 \mathrm{ppm}$ concentration for A. calandrae on $C$. maculatus, $R$. dominica and $S$. oryzae respectively. Lowest mortalities 16.66, 27.61, and $25.83 \%$ were observed with $200 \mathrm{ppm}$ for A. calandrae on C. maculatus, $R$. dominica and $S$. oryzae respectively. Mortality of $A$. calandrae increases with an increase in $\mathrm{DE}$ concentration. $S$. oryzae showed higher mortality $(63.81 \%)$ for A. calandrae at maximum dose in bioassay (Fig. 4).

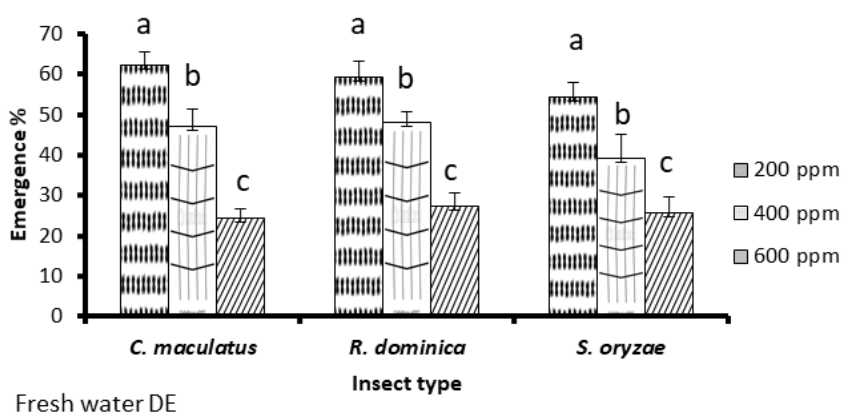

Figure 5. Comparison of means of percent emergence of tested insects, $C$. maculatus $(\mathrm{F}=6.07 ;(P<0.001)$, $R$. dominica $(\mathrm{F}=11.6 ; \quad P<0.001), \quad$ S. oryzae $(\mathrm{F}=21.18 ;(P<0.001)$ at different dose $(\mathrm{ppm})$ of Perma Guard diatomaceous earth after 14 days time interval.

The results reveal that for fresh water DE the highest emergence $62.26,59.34$ and $54.81 \%$ were recorded in $200 \mathrm{ppm}$ concentration for A. calandrae on $C$. maculatus, $R$. dominica and $S$. oryzae respectively. Lowest emergence 24.41, 27.21 and $25.70 \%$ was observed with $200 \mathrm{ppm}$ concentration for A. calandrae on C. maculatus, $R$. dominica and $S$. oryzae respectively. Emergence of tested insects decreases with an increase in DE concentration. C. maculatus shows higher emergence $62.44 \%$ at minimum dose in bioassay (Fig. 5).

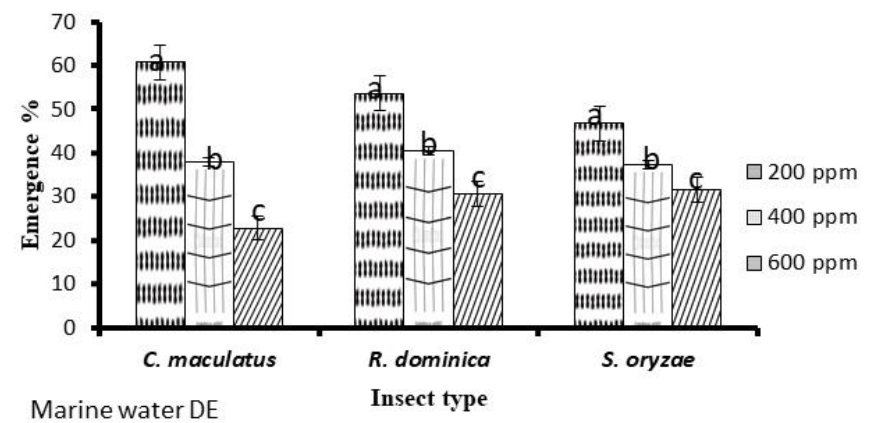

Figure 6. Comparison of means of percent emergence of tested insects, $C$. maculatus $(\mathrm{F}=6.07 ;(P<0.001)$, R. dominica $(\mathrm{F}=11.6 ; \quad P<0.001), \quad S$. oryzae $(\mathrm{F}=21.18 ; P<0.001)$ at different dose $(\mathrm{ppm})$ of Celite diatomaceous earth after 14 days time interval
The results reveal that for marine water DE the highest emergence 60.66, 53.64 and 46.71\% were recorded in 200 ppm concentration for A. calandrae on $C$. maculatus, $R$. dominica and $S$. oryzae respectively. Lowest emergence $22.81,30.60$ and $31.63 \%$ were observed with $600 \mathrm{ppm}$ concentration of diatomaceous for $A$. calandrae on $C$. maculatus, $R$. dominica and $S$. oryzae respectively. Tested insects showed higher emergence at lower concentration as compared to higher concentration applied. C. maculatus shows higher emergence $(60.661 \%)$ at minimum dose in bioassay (Fig. 6).

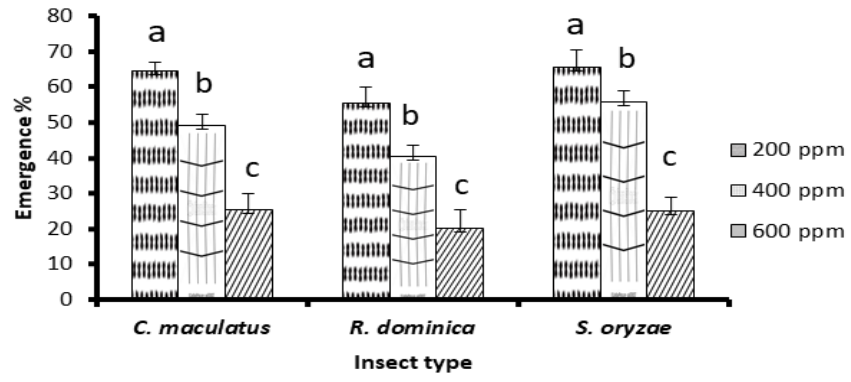

Figure 7. Comparison of means of percent emergence of $\boldsymbol{A}$. calandrae on tested insects, $C$. maculatus $(\mathrm{F}=29.13 ; \quad P<0.001), \quad R$. dominica $\quad(\mathrm{F}=8.62$; $P<0.001), \quad S$. oryzae $(\mathrm{F}=2.59 ; \quad P<0.001)$ at different dose (ppm) of Perma Guard diatomaceous earth after 14 days time interval

The results reveal that for fresh water DE, the highest emergence of $64.51,55.25$ and $69.65 \%$ were recorded in 200 ppm concentration for A. calandrae on $C$. maculatus, $R$. dominica and $S$. oryzae, respectively. Lowest emergence 25.22, 20.06 and $24.96 \%$ were observed with 600 ppm concentration for A. calandrae on $C$. maculatus, $R$. dominica and $S$. oryzae, respectively. Emergence of $A$. calandrae decreased with an increase in DE concentration. A. calandrae showed higher emergence at lower dose applied. S. oryzae shows higher emergence $(69.65 \%)$ at minimum dose of 200ppm in bioassay (Fig. 7).

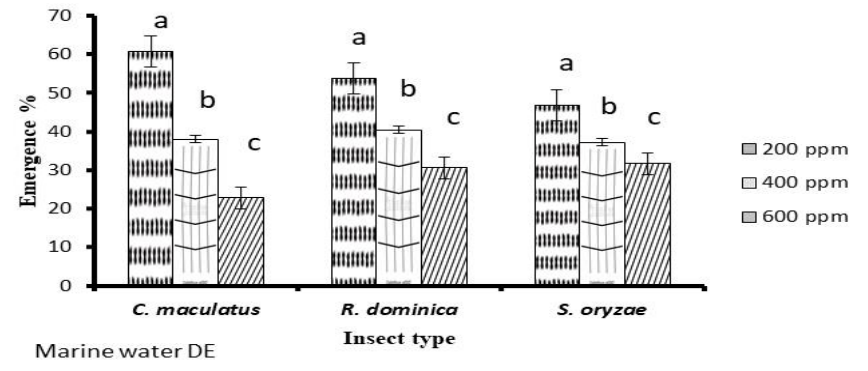

Figure 8. Comparison of means of percent emergence of A. calandrae on tested insects, $C$. maculatus $(\mathrm{F}=29.13 ; \quad P<0.001), \quad R$. dominica $\quad(\mathrm{F}=8.62$; $P<0.001), \quad S$. oryzae $(\mathrm{F}=2.59 ; \quad P<0.001)$ at different dose (ppm) of Celite diatomaceous earth after 14 days time interval 
The results reveal that for marine water DE the highest emergence were recorded in $200 \mathrm{ppm}$ treatment 60.66, 53.64 and $46.71 \%$ for $A$. calandrae on C. maculatus, $R$. dominica and $S$. oryzae respectively. Lowest emergences were observed with $600 \mathrm{ppm}$ treatment, 22.8130 .60 and $31.63 \%$ for $A$. calandrae on $C$. maculatus, $R$. dominica and $S$. oryzae respectively. A. calandrae showed higher emergence at lower concentration applied. $C$. maculatus shows higher emergence $(60.66 \%)$ at minimum dose of 200ppm in bioassay (Fig. 8).

\section{DISCUSSION}

The results in our experiments revealed that the highest mortality of $C$. maculatus was recorded at $600 \mathrm{ppm}$ concentration of fresh water and marine water formulation of DE against $S$. oryzae. This showed the adverse effect of DE on survival of pests. Lowest mortality $11.05 \%$ was observed with 200 ppm concentration for $R$. dominica and $10.14 \%$ for C. maculatus. This showed that mortality at low dose caused to DE treatment and pest showed susceptibility towards DE. Similarly Moras et al. (2006) found results that Keepdry® was effective for $S$. oryzae species at higher doses and kills the tested beetle maximum but survival for the $S$. oryzae was high at lower doses, the same DE was effective at higher doses against $S$. zeamais on maize and $A$. obtectus on beans after 3 days of exposure. This result shows that the mortality depends on dose rate; higher dose shows more mortality as compared to lower dose rate. Our result was also satisfied by Ceruti et al. (2006) showed that Keepdry® killed completely all population of $S$. oryzae adults on pearl millet seeds treated with $1000 \mathrm{ppm} \mathrm{DE}$ dose after $14 \mathrm{~d}$ of exposure at $25^{\circ} \mathrm{C}$.

Wakil et al., 2014 concluded in experiment by using (ProtectIt) DE against adults of $R$. dominica (F.). The 500 and 600 ppm dose rates were highly effective resulting in about $100 \%$ mortality in three weeks of exposure interval to treated wheat. Mortality of insects depends on the time intervals of exposed treatment as well as concentration applied.

Different insects have different susceptibility to DE some populations of insects, which are more tolerant can be significantly controlled by DE formulations (Rigaux et al., 2001). In present study, almost all the bruchids in control treatment infesting grains developed and emerged to a new generation of $C$. maculatus, $R$. dominica and $S$. oryzae, However, treatment with lower dose mortality was lower and higher emergence found for all the tested insects.

The highest mortality $66.86 \pm 1.95 \%$ was recorded in $600 \mathrm{ppm}$ concentration for A. calandrae on S. oryzae in fresh water DE treatment and $63.81 \pm 2.28 \%$ was recorded for A. calandrae on $S$. oryzae in Marine water DE treatment. Lowest mortality $19.66 \pm 2.09 \%$ was observed with $200 \mathrm{ppm}$ concentration for A. calandrae on $C$. maculatus and $16.66 \pm 2.11 \%$ for $A$. calandrae on C. maculatus. Alan and Fields (2012) ound the same result on treating the $A$. calandrae with $\mathrm{DE}$ and conclude that the DE mode of action is the same for all the insects regardless of predator and prey. Its capability of killing equally affects all the insects.

Cheaseng et al., 2017 successfully control the specie $S$. zeamais, by treatment of Keepdry®. $100 \%$ of insect mortality was observed after 20 days of application.

The highest emergence $62.44 \%$ and $60.66 \%$ were recorded in $600 \mathrm{ppm}$ concentration for A. calandrae on C. maculatus for fresh water and marine water DE treatment respectively. Lowest emergence $24.41 \%$ and $22.81 \%$ was observed with $200 \mathrm{ppm}$ concentration for A. calandrae on C. maculatus for fresh water and marine water DE treatment respectively.

Fieldsa, and Korunic in (2010) found that lower dose treatments of DE emergence of tested insects found greater than the higher dose treatment. Arthur in (2010) found that $A$. calandrae reproduce in higher rate when abundant amount of host insects found in favorable environment conditions.

For fresh water DE the highest emergence $65.65 \%$ were recorded in $600 \mathrm{ppm}$ concentration for A. calandrae on $S$. oryzae. For marine water DE the highest emergence were recorded in $600 \mathrm{ppm}$ treatment $60.66 \%$ for A. calandrae on C. maculatus. Lowest emergence $20.06 \%$ was observed with $200 \mathrm{ppm}$ concentration for $A$. calandrae on $R$. dominica. Lowest emergence was observed with $200 \mathrm{ppm}$ treatment, $22.81 \%$ for A. calandrae on C. maculatus.

Wakil and Shabbir 2013 evaluate the mortality and emergence of tested insects by application of SilicoSec $₫$ on treated grains. Grains were allowed to infest by $S$. ryzae adults and all the exposed adults were removed and progeny production was estimated. Data collected after 3 weeks showed complete suppression of insects achieved and no progeny found time interval and dose rate played a significant role for the suppression of tested insects and their progeny. In present study the DE treatment equally affects the mortality and progeny production of the tested insects, parasitoid and its efficacy. Effect of DE on parasitoid and tested insects reduce the production of tested insect and also affect the parasitism of $A$. calandrae toward the tested insects. Mortality is directly proportional to the exposure time and dose rates applied.

Conclusion: Higher dose of DE treatment showed mortality effect both on the parasitoid and pests however use of proper dose of DE along with biological control can be very effective for the control of insect pests. In conclusion, the findings of this study indicate that, both DEs formulation i.e., Fresh water (Perma Guard) and Marine water (Celite) could provide excellent control of insect pests (internal feeders) used, when treated at $600 \mathrm{ppm}$ causing mortality as compared with those at lower dose rates. Higher dose used caused the mortality of population of both the insect pests and the parasitoid and reduce emergence ultimately. In the dosages of DE varying from 200 to $600 \mathrm{ppm}$ can be used in stored cowpea, wheat and rice, as grain protectants to reduce the population of insect 
pests, however concentrations of DE applied also showed adverse effect on the parasitoids population.

\section{REFERENCES}

Abbott, W. S. 1925. A method of computing the effectiveness of an insecticide. J. Econ. Entomol., 18: 265-267.

Alan K.D. and P.G. Fields. 2012. Heat combined with diatomaceous earth to control the confused flour beetle (Coleoptera: Tenebrionidae) in a flour mills. J. Stored Prod. Res. 38:11-22

Arthur, F.H. 2002. Survival of Sitophilus oryzae (L.) (Coleoptera: Curculionidae) on wheat treated with diatomaceous earth: impact of biological and environmental parameters on product efficacy. J. Stored Prod. Res. 38:305-313.

Arthur, F.H. 2010. Immediate and delayed mortality of Oryzaephilus surinamensis (L.) exposed on wheat treated with diatomaceous earth: effects of temperature, relative humidity, and exposure interval. J. of Stored Prod. Res. 37:13-21.

Athanassiou, C.G., N.G. Kavallieratos, F.C. Tsaganou, B.J. Vayias, C.B. Dimizas and C.T. Buchelos. 2003. Effect of grain type on the insecticidal efficacy of Silico Sec against Sitophilus oryzae (L) (Coleoptera: Curculionidae). Crop Prot. 22:1141-1147.

Athanassiou, C.G., B. J. Vayias, C.B. Dimizas, N.G. Kavallieratos, A.S. Papagregoriou and C.T. Buchelos. 2005. Insecticidal efficacy of D.E against Sitophilus oryzae (L.) (Coleoptera: Curculionidae) and Tribolium confusum du Val (Coleoptera: Tenebrionidae) on stored wheat: influence of dose rate, temperature and exposure interval. J. Stored Prod. Res. 41: 47-55.

Athanassiou, C.G., N.G. Kavallieratos, B.J. Vayias, Z. Tomanovic, A. Petrovic, V. Rozman, Adler, Z.C. and D. Milovanovic. 2011. Laboratory evaluation of D.E deposits mined from several locations in central and southeastern Europe as potential protectants against coleopteran grain pests. Crop Prot. 30:329-339.

Ceruti, F.C., S.M.N. Lazzari and F.A. Lazzari. 2006. Combination of diatomaceous earth and temperature to control Sitophilus zeamais (Coleoptera: Curculionidae) in pearl millet seeds. Proceedings of the Ninth International Working Conference on Stored-product Protection, Campinas, ABRAPOS. 695-700.

Cheaseng, P. K., G. M Simiyu, P. W. and P. Gupta. 2017 Assessment of efficacy of unstabilized pyrethrins and diatomaceous earth admixture on Sitophilus zeamais in maize grains. J. Entomology. 2:543-552.

Fieldsa, P. and Z. Korunic. 2010. Routes of transpiratory water loss in a dry-habitat Tenebrionid beetle. J. Exp. Bio. 157:425-437.

Ghimire, M.N., and T.W. Phillips. 2008. Effects of prior experience on tested selection and tested utilization by two populations of Anisopteromalus calandrae (Hymenoptera: Pteromalidae). Environ. Entomol. 37:1300-1306.

Gokhman, V.E. and A.V. Timokhov. 2003. Tested preferences of parasitic wasps of the Anisopteromalus calandrae species complex (Hymenoptera: Pteromalidae). Acta. Soc. Zoo. Bohem. 67:35-39.

Hoedjes, K.M., H.M. Kruidh of, M.E. Huigens, M. Dicke and H.M. Smid. 2011 Natural variation in learning rate and memory dynamics in parasitoid wasps: opportunities for converging ecology and neuroscience. Proc. Biol. Sci.278:889-897.

Islam, W., D. W. Hagstrum, C. Reed and S. M. H. Kabir. 2003. Studies on the ectoparasitoid, Anisopteromalus calandrae How. (Hymenoptera: Pteromalidae) as a biocontrol agent against the Bore, Rhyzopertha dominica (Saudi Arabia). J. Stored Prod. Res. 32:137-140.

Islam, W. 2006. The biology of Anisopteromalus calandrae How. ectoparasitoid on Callosobruchus chinensis ( L). Bangladesh. J. Zool. 21:123-132.

Ishii, Y. 2008. Coexistence mediated by a common predator in three species tested-parasitoid experimental systems. PhD thesis, The University of Tokyo.

Ishii, Y. and M. Shimada. 2012. Learning predator promotes coexistence of prey species in tested parasitoid systems. Proc. Nat. Acad. Sci. USA. 109:5116-5120.

Konishi, T.C., K. Narendran, T. Imamura and P. Visarathanonth. 2004. Chalcididae (Hymenoptera) from rice stores in Thailand, with descriptions of two new species. Environ. Entomol. 26:106-118.

Kavallieratos, N.G., C.G. Athanassiou, B.J. Vayias, and S.N. Maistrou. 2007. Influence of temperature on susceptibility of Tribolium confusum (Coleoptera: Tenebrionidae) populations to three modified diatomaceous earth formulations. J. Entomol. 90:616625.

Kavallieratos, N.G., C.G. Athanassiou, F.G. Pashalidou, N.S. Andris and Z. Tomanovic. 2005. Influence of grain type on the insecticidal efficacy of two diatomaceous earth formulations against Rhyzopertha dominica (F.) (Coleoptera: Bostrychidae). Pest Manag. Sci. 61:660666.

Moras, A., F. M. Pereira, M. Oliveira, I. Lorini, M. A. Schirmer, M. C. Elias, 2006. Diatomaceous earth and propionic acid to control Sitophilus oryzae and Oryzaephilus surinamensis rice stored grain pests. Proceedings of the Ninth International Working Conference on Stored-product Protection, Campinas, ABRAPOS. pp. 823-828.

Perez-mendoza, J., J. E. Baker, F. H. Arthur and P. W. Flinn. 1999. Effects of Protect-It on Efficacy of Anisopteromalus calandrae (Hymenoptera: Pteromalidae) Parasitizing Rice Weevils (Coleoptera: Curculionidae) in Wheat. Envir. Entom. 28:529-534. 
Rigaux, M., Haubruge, E., P. G. Fields, 2001. Mechanisms for tolerance to diatomaceous earth between strains of Tribolium castaneum. Entomologia Experimentalis et Applicata. 101: 33-39.

Sasakawa K, M. Sato and M. Shimada.2012. Additional notes on Anisopteromalus sp. (Hymenoptera: Pteromalidae), the sibling species of a parasitic wasp of stored product pests, Anisopteromalus calandrae (Howard): a new alternative tested, an eye color mutant and DNA barcodes. Entomol. Sci. 15:349-351.

Sidra-Tul-Muntaha, Muhammad Sagheer, Mansoor-ul-Hasan and Shahbaz Talib Sahi. 2017. Repellent and Growth Inhibitory Impact of Plant Extracts and Synthetic Pyrethroids on three Strains of Callosobruchus chinensis L. Pak. J. Zool.49: 581-589.
Subramanyam, B. and R. Roesli. 2000. Inert dusts. In: Subramanyam, Bh.,Hagstrum, D.W. (Eds.), Alt. Pest. Stored Prod. IPM. Kluwer Academic Publishers, Dordrecht.17:321-380.

Wakil, W., M. Ashfaq, A. Shabbir and A. Javed. 2014. Efficacy of diatomaceous earth (protect-it) as a protectant of stored wheat against Rhyzopertha dominica (F.) (Coleoptera: Bostrychidae). J. Stored Prod. Res. 31:8797.

Wakil, W. and A. Shabbir, 2013. Evaluation of diatomaceous earth admixed with rice to control sitophilus oryzae (L.) (Coleoptera: Curculionidae). J. Econ. Entomol. 93:526532. 